\title{
Application of Adaptive Virtual Environments Through Biofeedback for the Treatment of Phobias ${ }^{+}$
}

\author{
João Donga ${ }^{1, *}$, Paulo Veloso Gomes ${ }^{2}$, António Marques ${ }^{2}$, Javier Pereira ${ }^{3}$ and João Azevedo ${ }^{1}$ \\ 1 LabRP, Psychosocial Rehabilitation Laboratory, School of Media Arts and Design, \\ Polytechnic Institute of Porto, 4200-465 Porto, Portugal; joaoazevedo@esmad.ipp.pt \\ 2 LabRP, Psychosocial Rehabilitation Laboratory, School of Allied Health Technologies, Polytechnic Institute \\ of Porto, 4200-465 Porto, Portugal; pvg@ess.ipp.pt (P.V.G.); ajmarques@ess.ipp.pt (A.M.) \\ 3 CITIC-Research Center of Information and Communication Technologies, University of A Coruña, \\ 15071 A Coruña, Spain; javier.pereira@udc.es \\ * Correspondence: jpd@esmad.ipp.pt \\ + Presented at the 3rd XoveTIC Congress, A Coruña, Spain, 8-9 outubro 2020.
}

Published: 25 August 2020

\begin{abstract}
This study proposes solutions to help people with phobias through the use of virtual environments that allow a contact between the subjects and these phobias. Using neurofeedback, the systems, depending on the emotional state of the user, adapt the scenarios allowing more or less intensity. The phobias these systems treat are social phobia, entomophobia and claustrophobia. The solutions have been developed using Unity, Muse 2 and Vive HTC.
\end{abstract}

Keywords: social phobia; entomophobia; claustrophobia; virtual reality; immersive environments; brain-computer interface; virtual reality exposure therapy; electroencephalography; biofeedback

\section{Introduction}

A specific phobia consists of fear and anxiety about a particular situation or object. The situation or object is generally avoided when possible; but if exposure does occur, anxiety develops quickly. Anxiety can intensify to the level of a panic attack. People with a specific phobia usually recognize that their fear is irrational and excessive. There are several possible treatments that must be adequate according to the clinical condition. One such treatment is exposure therapy [1]. Patients confront and keep in touch with what they fear and avoid until anxiety gradually decreases through a process called habituation. Typically, therapists start with moderate exposure. When patients are comfortable with an exposure level, the exposure level is increased. Therapists continue to increase the level of the exposure until patients are able to tolerate normal interaction with the situation or object. Using solutions implemented in Virtual Reality (VR) has significative advantages [2], as it is possible to expose patients to situations or objects related to phobias in a controlled manner [3]. In the real world, the use of real animals is very difficult and controlling their behaviors is a complex challenge. The number of animals used also implies costs, and the simulation of situations involves complex logistical issues [4]. The use of a virtual reality-controlled environment allows the therapist to insert the necessary elements to expose the user to the agent that causes the phobia [5]. It is possible to vary its quantity and the intensity of the exposure, and to repeat the process as many times as necessary.

This work intends to reproduce the exposure therapy, and allow that exposure to change in intensity according to the patient's emotional state. 


\section{Materials and Methods}

Two VR solutions were developed with the use of portable electroencephalograms (EEG) that read the user's biofeedback, leading the virtual environments to adapt according to the emotional state via the strategy chosen by the therapist. Virtual Therapy and FearNot are the projects developed by the research group LabRP (Psychosocial Rehabilitation Laboratory) of the School of Allied Health Technologies, and the School of Media Arts and Design, both belonging to the Polytechnic Institute of Porto.

FearNot allows people with insect phobias or claustrophobia to be exposed to environments with insects in varying numbers, or to a room with varying dimensions and brightness, depending on biofeedback reading (Figure 1).

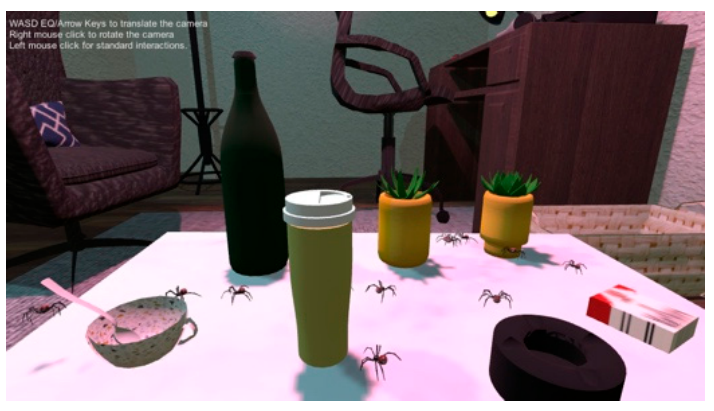

(a)

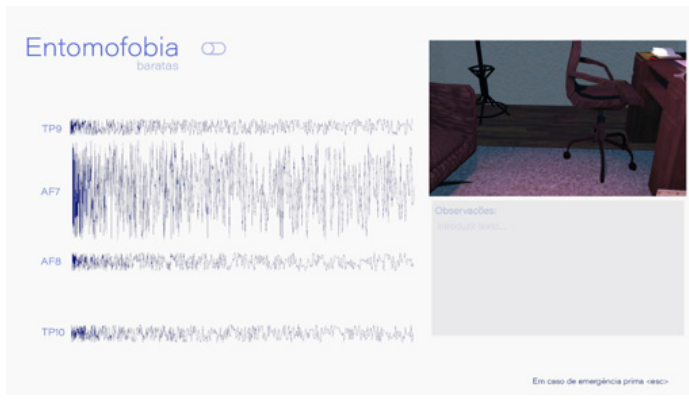

(b)

Figure 1. (a) Virtual environment with spiders; (b) Screen used by the therapist to read the electroencephalogram.

Virtual Therapy applies to people with social phobia, and exposes the patient to a social experience in a professional context that consists of an oral presentation to the public in an auditorium. It designs an automatic response to user performance based on biomedical data, and varies the number of spectators in the auditorium and their behavior (Figure 2).

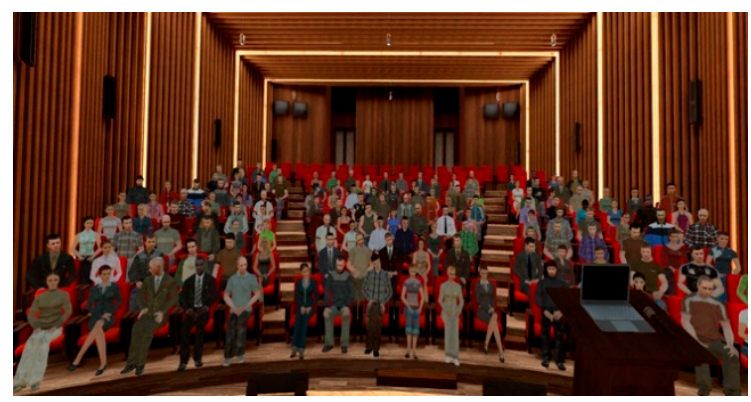

(a)

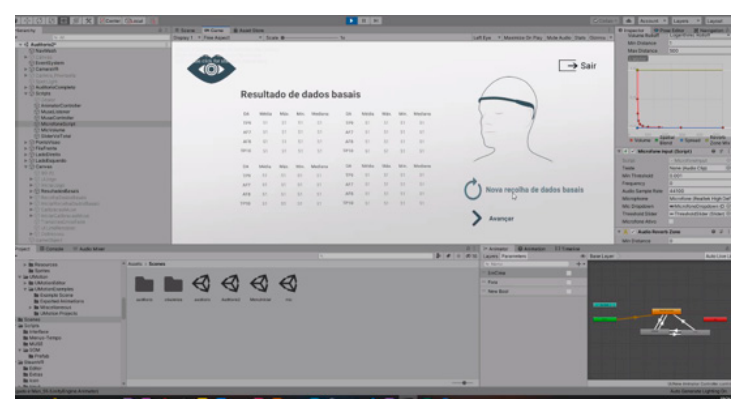

(b)

Figure 2. (a) Virtual environment simulating an auditorium; (b) Control Menu.

\section{Results}

For the time being, no results are available to draw definitive conclusions about the impact of this study. Even so, the observations made during the tests reflects the fact that the participants show a high level of motivation, interest and involvement towards the activities developed. However, it is necessary to wait for the final collection of data and its subsequent analysis, as well as future tests with larger samples, to determine if the project has a real impact on the quality of life of people with the related phobias. 
Author Contributions: Conceptualization, J.D.; methodology, J.D. and P.V.G.; writing - review and editing, J.D.; P.V.G. and J.A.; supervision, A.M. and J.P; project administration, A.M. and J.P. All authors have read and agreed to the published version of the manuscript.

Funding: This research received no external funding.

Acknowledgments: The authors would like to thank the Multimedia students that developed Virtual Therapy (Catarina Baldaia, Gil Araújo) and FearNot (Daniela Martins, Mariana Carvalho, Margarida Santos).

Conflicts of Interest: The authors declare no conflict of interest.

\section{References}

1. Gorini, A.; Riva, G. Virtual reality in anxiety disorders: the past and the future; Expert Review of Neurotherapeutics, 2008, 8, 215-233. doi:10.1586/14737175.8.2.215

2. Cláudio, A.P.; Carmo, M.B.; Pinheiro, T.; Esteves, F.; Lopes, E. Virtual Environment to Treat Social Anxiety; In BT-Design, User Experience, and Usability. Health, Learning, Playing, Cultural, and Cross-Cultural User Experience; Marcus, A., Ed.; Springer: Berlin/Heidelberg, Germany, 2013; pp. 442-451.

3. Gebara, C.M.; Barros-Neto, T.P.; Gertsenchtein, L.; Lotufo-Neto, F. Virtual reality exposure using threedimensional images for the treatment of social phobia. Braz. J. Psychiatry 2016, 38, 24-29. doi:10.1590/15164446-2014-1560

4. Musalek, M.; Vasek, L. Possibilities of using virtual reality as a means for therapy from fear of spiders. In MATEC Web of Conferences; EDP Sciences: Ulis, France, 2019; Volume 292.

5. Meyerbröker, K.; Emmelkamp, P.M.G. Virtual Reality Exposure Therapy for Anxiety Disorders: The State of the Art. In Advanced Computational Intelligence Paradigms in Healthcare 6; Springer: Berlin/Heidelberg, Germany, 2011; Volume 337, pp. 47-62.

(C) 2020 by the authors. Licensee MDPI, Basel, Switzerland. This article is an open access article distributed under the terms and conditions of the Creative Commons Attribution (CC BY) license (http://creativecommons.org/licenses/by/4.0/). 